Bond University

Research Repository

\title{
Media coverage of calls to rename low-risk cancers: a content analysis
}

Nickel, Brooke; Moynihan, Ray; Barratt, Alexandra; Brito, Juan P; McCaffery, Kirsten

Published in:

BMJ Open

DOI:

10.1136/bmjopen-2020-038087

\section{Licence:}

CC BY-NC

Link to output in Bond University research repository.

Recommended citation(APA):

Nickel, B., Moynihan, R., Barratt, A., Brito, J. P., \& McCaffery, K. (2020). Media coverage of calls to rename lowrisk cancers: a content analysis. BMJ Open, 10(7), [e038087]. https://doi.org/10.1136/bmjopen-2020-038087

\footnotetext{
General rights

Copyright and moral rights for the publications made accessible in the public portal are retained by the authors and/or other copyright owners and it is a condition of accessing publications that users recognise and abide by the legal requirements associated with these rights.
}

For more information, or if you believe that this document breaches copyright, please contact the Bond University research repository coordinator. 


\title{
BMJ Open Media coverage of calls to rename low- risk cancers: a content analysis
}

\author{
Brooke Nickel (D) , ${ }^{1,2}$ Ray Moynihan, ${ }^{1,3}$ Alexandra Barratt, ${ }^{1}$ Juan P Brito, ${ }^{4}$ \\ Kirsten McCaffery ${ }^{1,2}$
}

To cite: Nickel B, Moynihan R, Barratt A, et al. Media coverage of calls to rename low-risk cancers: a content analysis. BMJ Open 2020;10:e038087. doi:10.1136/ bmjopen-2020-038087

- Prepublication history and additional material for this paper are available online. To view these files, please visit the journal online (http://dx. doi. org/10.1136/bmjopen-2020038087).

Received 27 February 2020 Revised 03 June 2020 Accepted 09 June 2020

A) Check for updates

(c) Author(s) (or their employer(s)) 2020. Re-use permitted under CC BY-NC. No commercial re-use. See rights and permissions. Published by BMJ.

${ }^{1}$ Wiser Healthcare, School of Public Health, Faculty of Medicine and Health, The University of Sydney, Sydney, New South Wales, Australia ${ }^{2}$ Sydney Health Literacy Lab, School of Public Health, Faculty of Medicine and Health, The University of Sydney, Sydney, New South Wales, Australia ${ }^{3}$ Centre for Research in Evidence-Based Practice, Faculty of Health Sciences and Medicine, Bond University, Gold Coast, Queensland, Australia

${ }^{4}$ Division of Endocrinology,

Diabetes, Metabolism \&

Nutrition, Mayo Clinic, Rochester, Minnesota, USA

Correspondence to

Dr Brooke Nickel;

brooke.nickel@sydney.edu.au

\section{ABSTRACT}

Objectives The use of more medicalised labels can increase both concern about illness and the desire for more invasive treatment. This study analyses the media's coverage of an Analysis article in The BMJ which generated a large amount of high-profile international media coverage. It aims to understand how to better communicate messages about low-risk cancers and overdiagnosis to the public.

Design Content analysis of media coverage.

Setting Media was identified by Isentia Media Portal, searched in Google News and cross-checked in Factiva and Proquest databases from August 2018.

Methods Media headlines, full text and open access public comments responding to the coverage on the article proposing to 'rename low-risk conditions currently labelled as cancer' were analysed to determine the main themes. Results 45 original media articles and their associated public comments $(n=167)$ were identified and included in the analysis. Overall, headlines focused on cancer generally and there was little mention of 'low-risk', 'overdiagnosis' or 'overtreatment'. The full text generally presented a more balanced view of the evidence and were supportive of the proposal, however, public responses tended to be more negative towards the idea of renaming low-risk cancers and indicated confusion. Comments seemed to focus on the headlines rather than the full article.

Conclusions This study offers a novel insight into media coverage of the complex and counterintuitive problem of overdiagnosis. Continued deliberation on how to communicate similar topics to the public through the mainstream media is needed. Future work in the area of low-risk cancer communication should consider the powerful impact of people's previous experience with a cancer diagnosis and the criticism about being paternalistic and concealing the truth from patients.

\section{INTRODUCTION}

Over the past few decades, our understanding of cancer has changed. Evidence now demonstrates that some cancers are non-growing or so slow growing that they will never cause harm to an individual if left undetected or untreated. This has raised growing concern about overdiagnosis in cancer. ${ }^{12}$ Overdiagnosis is broadly agreed to be a diagnosis that causes more harm than good, ${ }^{3}$ and can result in subsequent overtreatment. While
Strengths and limitations of this study

This is the first study to analyse the media and publics' response to a proposal to rename low-risk cancers, a potential strategy to reduce overdiagnosis and overtreatment.

- The article received a large amount of high-profile international media coverage which allowed reach in a diverse range of audiences.

- Much of the radio and television (TV) media was not accessible following broadcast so was not able to be included in the analysis.

- Comments analysed came from a small proportion of the total reader/viewership and may therefore not be representative of the overall public's view on these topics.

there is now evidence of overdiagnosis across a number of types of low-risk cancers, the strongest evidence has been shown in localised prostate cancer (Gleason $\leq 6),{ }^{4}$ low-grade ductal carcinoma in situ (DCIS) of the breast ${ }^{5}$ and low-risk papillary thyroid cancer. ${ }^{6}$

Given the potential harms of overtreatment of these low-risk cancers, active monitoring is now recognised as a safe and effective management option. In localised prostate cancer active monitoring has been a recommended management option for a number of years, while in low-risk papillary thyroid cancer it has recently been suggested for very low-risk tumours ${ }^{7}$ and is currently being evaluated in randomised trials internationally for low-grade DCIS. ${ }^{8-10}$ However, while conservative management approaches, such as active monitoring, are becoming an option for some patients with low-risk cancer, there is still a strong perception that aggressive immediate treatments are always required. ${ }^{11}$ The cancer label currently used to describe these low-risk conditions can affect patient's psychological responses and make it harder for clinicians to recommend and patients to choose active monitoring as a management option because of a strong fear of cancer and assumption that surgery is best. ${ }^{12-16}$ Patients, therefore, risk being overtreated resulting in 
important surgical side effects and consequences on their quality of life.

In 2018 we wrote an Analysis article in The $B M J^{17}$ proposing removal of the cancer label for low-risk lesions where there is evidence of overdiagnosis and previous calls to replace the term cancer. The article generated significant high-profile media coverage internationally, including in major national newspapers and on television such as British Broadcasting Corporation (BBC) World news. The majority of what people know or learn about health now comes from media, which presents a major challenge for communicating about complex and counterintuitive concepts such as overdiagnosis. Previous research on the media has shown inaccurate coverage of published scientific papers, ${ }^{18}$ and overstate the benefits while downplaying the harms of medicine. ${ }^{19}$ All of this can shape the way people think about their own health. ${ }^{20} 21$ This study aims to analyse the media's coverage of the article, and responses to that coverage, to understand how to better communicate messages about low-risk cancers and overdiagnosis to the public.

\section{METHODS}

\section{Study design}

A content analysis ${ }^{22}$ of the media coverage of and initial public comments on our BMJ article proposing to 'rename low-risk conditions currently labelled as cancer' was conducted. We chose to conduct this analysis as the article received a significant amount of unexpected media attention, which is quite rare in response to one Analysis article. Content analysis combines qualitative and quantitative methods to analyse text data. It allows for the content and frequency of categories to be reported and is commonly used to analyse media. The study team included public health researchers with an interest in reducing overdiagnosis and overtreatment, a health psychologist, an epidemiologist and an endocrinologist.

\section{Procedure}

International media referring to the Analysis article were identified by Isentia Media Portal and provided to study authors by The University of Sydney's media team. Insentia is a subscribed service that collates media (online, print, broadcast and social media). Study authors also conducted a comprehensive search in Google News in the year following publication (August 2018-August 2019) and ran searches in Factiva and Proquest (both Australia and New Zealand Newstream and International Newstream) electronic databases from August 2018. Media on similar topics ${ }^{23} 24$ that were not directly related to The BMJ Analysis article were excluded. An academic librarian with expertise in systematic search design assisted with developing a search strategy to specifically capture media relating only to the Analysis article which used explicit keywords such as cancer, low-risk, overtreatment, anxiety, rename, The BMJ, Nickel, McCaffery, Moynihan, The University of Sydney. The database searches covered newspapers (print and online), webnews, major world and academic publications, blogs, magazines, broadcast (TV and radio), podcast transcripts and wire feeds/ services. Any additional media that was found in Google News, Factiva and Proquest was included in the analysis.

We extracted and analysed three domains across each media source: the headline, the full text of the media report and all available open access public comments responding to the coverage, in order to determine the main themes. Only original media sources were included with any duplicates published on other sources excluded. Replies to original public comments were also excluded.

\section{Patient and public involvement}

No patients involved. Open access public comments were analysed.

\section{Analysis}

The analysis followed an iterative process involving three members of the study team. First, the data were collated in Excel and organised by type of media. Next, two researchers (BN, RM) independently reviewed a subset of the article headlines, full text of articles and public comments (where applicable) and generated a list of recurring themes. These themes were discussed among the two researchers and checked by an additional research (KM) resulting in the development of an initial coding framework. The framework included separate codes for the headlines, full text and comments. Full text and comments could have more than one theme applied. In addition, we analysed and coded for the article's and comments overall support for the proposal to remove the cancer label for low-risk cancers, overall opposition to the proposal, or overall neutrality (neither supporting nor opposing the proposal). Due to their brevity, it was too difficult to classify the headlines into overall support or oppose categories.

The framework was tested by the two researchers and adjusted with further testing and discussion before being finalised. BN applied the final coding framework to all of the data (article headlines, full text of stories and comments), with RM double coding $>20 \%$. The level of agreement was tested using Cohen's kappa and indicated a strong level of agreement $(\mathrm{k}=0.86)$. Any discrepancies were discussed until a consensus was obtained. BN quantified coding categories and then compared the themes across the three categories to identify any differences or similarities. Descriptive statistical analysis was used to assess the frequency of each code and short quotations from the media text and public comments illustrating a diverse range of the themes are presented in the results.

\section{RESULTS}

A total of 132 media articles were identified. Articles were excluded if they were duplicates, that is, identical articles published on a different source $(n=49)$, had only published the original press release $(n=14)$ or could not be 
Table 1 Characteristics of the media coverage included in the analysis $(n=45)$

\begin{tabular}{lc}
\hline Media characteristics & Frequency $\mathbf{n}(\%)$ \\
\hline Type of media & \\
\hline Online news site & $20(44.4)$ \\
\hline Online newspaper & $11(24.4)$ \\
\hline Newspaper (print) & $6(13.3)$ \\
\hline Television news & $3(6.7)$ \\
\hline Academic media site & $2(4.4)$ \\
\hline Online magazine & $1(2.2)$ \\
\hline Radio & $1(2.2)$ \\
\hline Blog & $1(2.2)$ \\
Country & \\
\hline Australia and New Zealand & $23(51.1)$ \\
\hline UK and Europe & $8(17.8)$ \\
\hline USA and Canada & $6(13.3)$ \\
\hline Asia & $3(6.7)$ \\
\hline Middle East & $3(6.7)$ \\
\hline South America & $2(4.4)$ \\
\hline Public comments available & \\
\hline Yes & $14(31.1)$ \\
\hline No & $31(68.9)$ \\
\hline
\end{tabular}

accessed by the study authors or their media team $(n=24)$. This left 45 original media articles and news stories across various media sources (online supplementary appendix 1) and their associated public comments $(n=167)$ to be included in the analysis (table 1). The majority of media articles were from online news sites $(44 \%)$ and were from Australia and New Zealand (51\%). Only 14 of the 45 $(31 \%)$ articles had public comments available.

\section{Headlines}

Table 2 outlines the main coded themes in the headlines and provides an example and the frequency of each theme. The media headlines tended to focus on cancer generally, with some describing cancer as the ' $c$ word' and only a few of the headlines using the terms 'low-risk' which was used in the title of the original Analysis article published in The BMJ. Questioning, rethinking or debating cancer was the most prominent theme $(35.6 \%)$ that was identified in the headlines, followed by the idea that doctors are being told to or should avoid using the word cancer (20.0\%). There was only one headline $(2.2 \%)$ from an academic media source that used the word 'overdiagnosis' and only $6.7 \%$ of the media sources mentioned 'overtreatment', with a combined $11.1 \%$ mentioning anxiety and/or overtreatment. As expected, the headlines were short (mean word count=10) and catchy, but did not always reflect the underlying message of the article that removing the cancer label in low-risk conditions that are unlikely to cause harm if left untreated may help reduce overdiagnosis and overtreatment, for example 'Doctors being asked to stop using the 'c-word'.

\section{Article full text}

Table 3 outlines the main coded themes in the full text and provides an example and the frequency of each theme. The comprehensiveness in reporting of the Analysis article varied with the mean word count of the media articles and news stories was 608 words (ranging from 160 to 1594 words).

The majority $(n=33,73.3 \%)$ of the media's articles and news stories supported the proposal to rename lowrisk cancers, while only one $(2.2 \%)$ strongly opposed the proposal and $11(24.4 \%)$ were neutral and did not seem to support the proposal or oppose it. The latter articles and news stories gave a quite balanced view of the proposal stating both the arguments for and criticisms against. All of the articles discussed the evidence that points to the need for change and discussed the negative impact that the cancer label can have. In most of the media this consisted of a statement that recent evidence demonstrates that the term cancer can lead to higher levels of anxiety and greater preferences for more invasive treatments. It also included evidence on how our understanding of cancer has changed in recent years and now shows that some cancers can be non-growing or so slow growing that they will never cause harm if left untreated. The importance of the need for further discussion and deliberation about renaming low-risk cancers and feasibility of changing the terminology (ie, it has been done before) were also mentioned in about a quarter $(26.6 \%$ and $24.4 \%$, respectively) of the media.

The main opposing view highlighted in $24.4 \%$ of the media was the idea that providing better public education and communication to patients that all cancers aren't the same. The articles discussed that there are varying levels of risk and alternative less invasive treatment options

Table 2 Example and frequency of headline themes $(n=45)$

\begin{tabular}{|c|c|c|}
\hline Theme description & Example & $\%$ \\
\hline Push for change or overhaul by researchers & 'Push for cancer diagnosis overhaul' & 17.8 \\
\hline Reduce anxiety and/or overtreatment & 'Drop the C-word to reduce anxiety and overtreatment' & 11.1 \\
\hline
\end{tabular}


Table 3 Example and frequency of full text themes $(n=45)^{\star}$

\begin{tabular}{lll}
\hline Theme description & Example & $\%$ \\
\hline $\begin{array}{ll}\text { Overall supporting renaming proposal } \\
\text { Evidence points to need for change }\end{array}$ & $\begin{array}{l}\text { '...the call follows a growing body of evidence that describing a condition } \\
\text { using terms like 'cancer' can lead to an increased preference for more } \\
\text { invasive treatments.' }\end{array}$ \\
\hline
\end{tabular}

Negative impact of the cancer label on patients 'Using loaded labels such as 'cancer' can make patients more worried, the authors say, which can cause them to choose more aggressive management options - with more risk of harm.'

Importance of the need for further deliberation

'Cancer Council Australia chief executive Sanchia Aranda yesterday said it was time for a global roundtable on whether the word cancer should be used when communicating with low-risk patients.'

\begin{tabular}{l}
$\begin{array}{l}\text { Positive towards the feasibility of } \\
\text { changing the cancer label }\end{array} \quad$ '...the cancer label had already been removed from other tumours that \\
\hline
\end{tabular}

Doctors support the change

'I think it's a great initiative,' applauds Alvaro Rodríguez Lescure, vice president of the Spanish Society of Medical Oncology. 'Once you describe an injury as cancer, the patient wants to cut it clean, even though it's not really needed, and you can do an annual ultrasound, for example,' he argues.'

\section{Overall opposing renaming proposal}

Public education/better communication for patient instead of relabelling

Patients need to know the truth

Doctors concerns

'An alternative approach would be to recalibrate the thresholds so some very low-risk cancers are categorised as benign. If the public was educated that benign signifies very low-risk rather than no risk at all, then anxiety-inducing labels could be avoided.'

'The newish president of the Royal Australian College of General Practitioners Harry Nespolon says this proposal is dumbing down the advice given to patients. He says we always need to know the truth, the whole truth.'

'But the concern about renaming cancer is that some patients may not be as diligent as they should be in managing their condition, like having regular screenings and check-ups... If people with these low-risk conditions drop-out of active surveillance the danger is that they will then develop invasive cancers that are too late to treat.'

$\begin{aligned} & \text { Negative towards the feasibility of } \quad \text { 'I think it is very important that the oncologists know the natural history of } \\ & \text { changing the cancer label } \\ & \text { the various neoplasms...' }\end{aligned}$
Overall neither supporting nor opposing proposal†

${ }^{*}$ Full text could have more than one theme applied.

†Combination of both the supporting and opposing themes.

available instead of relabelling all low-risk cancers. The idea that changing the name of low-risk conditions would be concealing the truth from patients, and doctors concerns about follow-up and not taking the diagnosis as seriously were also highlighted as opposing views (discussed in $20.0 \%$ and $13.3 \%$ of the media, respectively).

\section{Comments}

Table 4 outlines the main coded themes in the comments and provides an example and the frequency of each theme. The public comments were less supportive towards the idea of renaming low-risk cancers, with approximately half $(49.7 \%)$ opposing the proposal. The themes for opposing the proposal varied, with the idea that 'cancer is cancer' $(19.2 \%)$, and the need for better education and communication for the public and patients $(18.6 \%)$ being the main two opposing themes.
Comments coded in these themes discussed the idea that changing the terminology would be misleading and it would be better to simple educate and communicate that cancer does not necessarily mean death and there can be varying risks. The need to reduce unnecessary anxiety and overtreatment was the main theme for supporting the renaming proposal. $13.2 \%$ of the comments acknowledged that the 'cancer' label may make patients anxious and more inclined to prefer more invasive treatments. Over a quarter (26.4\%) of the comments did not seem to be either supporting or opposing the proposal and $39.5 \%$ of the comments had other themes included in which a code did not apply or could not be coded at all. Personal stories about cancer drove many comments across the overarching themes (supporting, opposing and neither supporting/ 
Table 4 Example and frequency of comment themes $(n=167)^{\star} \dagger$

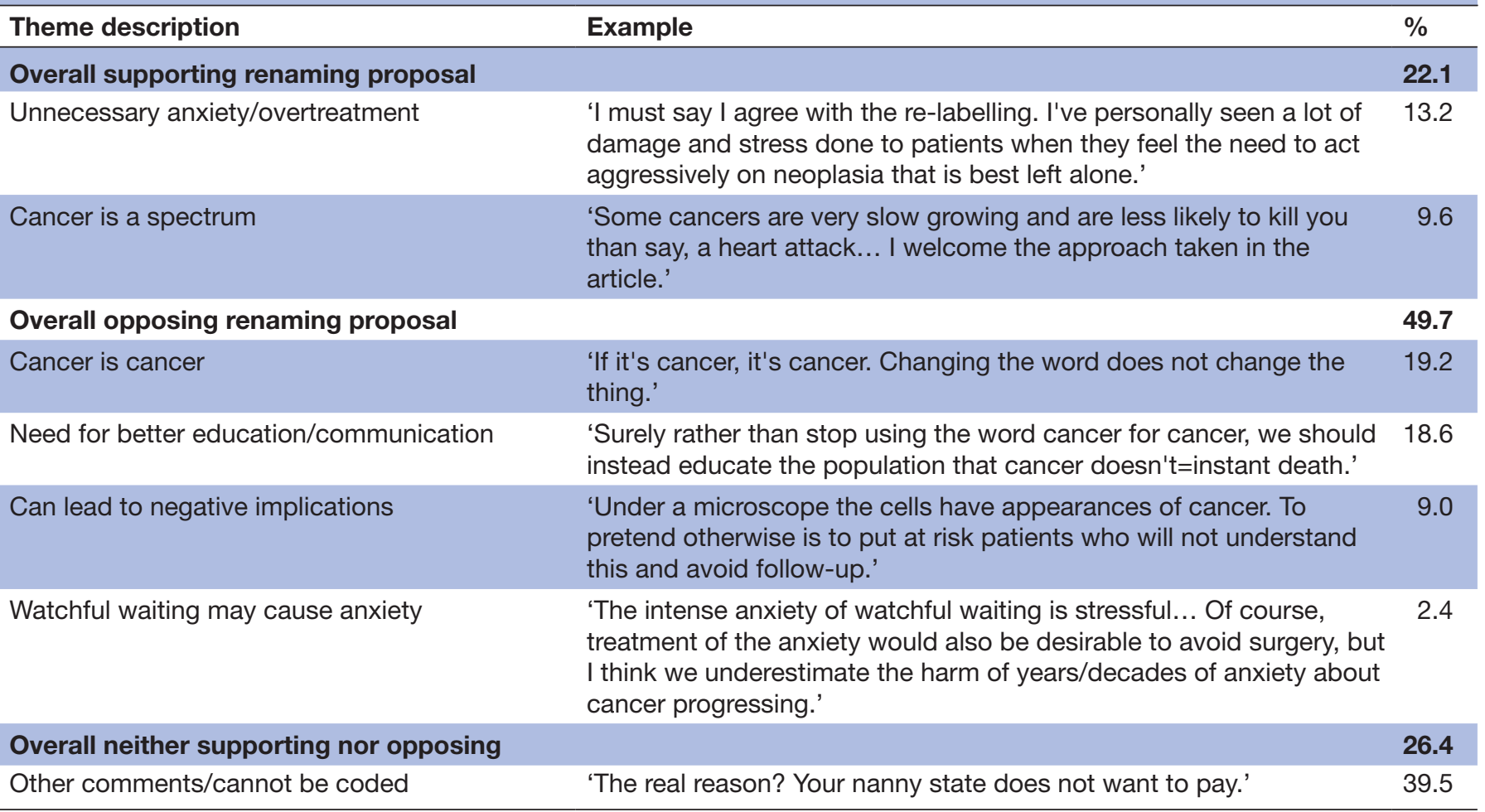

${ }^{*}$ Comments could have more than one theme applied.

†Not all media sources had public comments available, replies to original comments were excluded.

opposing). The mean word count for the comments was 88 words (ranging from 5 to 607 ).

\section{DISCUSSION}

Overdiagnosis and overtreatment of cancer is a serious concern in modern healthcare. ${ }^{12}$ This is the first study to analyse the media and publics' response to a proposal to rename low-risk cancers, a potential strategy to reduce overdiagnosis and overtreatment. Overall, we found that the coverage of the media reports was varied. Most full text articles and news stories reported the evidence well and tended to be positive towards the proposal. In all of the analysed media there was some reference to the evidence for why renaming low-risk cancers was being proposed and the potential harms associated with the cancer label. The articles and news stories often also highlighted the importance of the need for further deliberation before such a change could occur, the feasibility of the change, as well as concerns about the change and potential barriers to making the change. The public comments, however, tended to focus on the headlines, which were brief and usually framed the story around cancer generally.

Our study has important limitations and strengths. First, we were not able to access and analyse the majority of radio interviews and two Australian TV news stories from popular news programmes that were identified by Insentia Media Portal as the transcripts were not available in any of the databases or stored by The University of Sydney's media team or the broadcaster. Retrospective access to such media is difficult, however, saving media prospectively using platforms which store Uniform Resource Locators (URLs) and webpages so that they cannot be broken or destroyed (eg, VV Impact Tracker or WebSatchel) may help avoid this issue in the future. We also tried our best to crosscheck the media sources using various databases (Google News, Factiva and Proquest) but there still may have been other media that was not captured in the analysis. The majority of the media was from Australia and New Zealand, which occupies a small proportion of the worldwide coverage. Furthermore, comments that were analysed only came from a very small proportion of the total reader/viewership. While these comments add value to the analysis and give an insight into aspects of public understanding and acceptability of these topics, it cannot be seen in any way to be representative of the public's overall response. Lastly, although the analysis followed a robust process that has been successfully used by the study authors in the past, the coding framework was developed and the coding was carried out by two of the authors on The BMJAnalysis article and therefore may be subject to their views and biases on the topic. To our knowledge, however, this is the only study which has analysed the media's coverage of low-risk cancers and topics related to overdiagnosis and overtreatment. The large amount of high-profile national and international media coverage that The BMJ Analysis article attracted 
meant that its messages were widely disseminated across mainstream and academic media sites and programmes. This meant that the public had the opportunity to read, view, listen and in some cases respond to the proposal to rename low-risk cancers. Using the well-established method of content analysis ${ }^{22}$ allowed us to make rigourous judgements and valid inferences on the themes arising from the media reporting of our article.

How the media reports health and medical topics can have a profound influence on how the public perceives health risks and make decisions about their own health. ${ }^{2021}$ Given the brevity of media headlines however, and their purpose to pull readers in, they cannot convey the complexity of the full article to readers. For some of those readers making comments, the dominant notion of cancer and individual's previous experiences with cancer seemed to overshadow the article's main messages. Many of those who responded felt that 'cancer is cancer' and renaming it would be concealing the truth from patients. Similar to previous findings, ${ }^{25}$ some of the public as well as clinicians who were interviewed in the media also believed that better public and patient education about the lowrisk nature of some cancers could be a better strategy to curtail overdiagnosis and overtreatment. Acceptability and difficultly in understanding the strategy to rename low-risk cancers in order to avoid the harms associated with the cancer label and overdiagnosis and overtreatment is not surprising. The general lack of awareness of these topics has been found across a number of recent studies $^{25-31}$ and the highly positive and widespread public enthusiasm towards cancer screening and early detection has been documented. ${ }^{32}{ }^{33}$ It is important to note that the underlying aim of the original Analysis article was to try and explain the complexities of the low-risk nature of some cancers and provide as much scientific data about the harms as well as the benefits of diagnosis and treatment of low-risk cancers and the potential impact that comes from the cancer label. Communication that follows such an article or study may need to better provide the evidence in a way that people can relate to so that they become more generally aware of these risks and benefits. It also should be noted that the title of the original Analysis article was about 'renaming' low-risk cancers rather than 'reclassifying' or 'recalibrating' low-risk cancers which may have understandably led to a misinterpretation that we were advocating to just give these conditions new names and be deceptive to patients rather than thinking about or classifying the entire condition differently.

It has been shown that the concept of overdiagnosis is difficult to understand and highly emotive as it can often be driven by fear and discomfort with uncertainty. ${ }^{34}$ As such, overdiagnosis is often misunderstood or misinterpreted. ${ }^{35} 36$ The media can play a major role in facilitating broader public discussion of the concept of overdiagnosis and overtreatment, potentially influencing public, patient and clinician beliefs, and health systems change. ${ }^{37} 38$ This study offers a novel insight into media coverage of the complex and counter-intuitive problem of overdiagnosis.
It demonstrates the need for on-going deliberations about the optimum communication of similar topics to the public via mainstream media. Notably, future work specifically in the area of low-risk cancer communication will need to consider the powerful impact of people's previous experience with a cancer diagnosis and the criticism about being paternalistic and concealing the truth from patients, as this has also been shown in our focus group work on the topic. ${ }^{25}$ As new screening, testing and imaging technologies continue to emerge identifying smaller and smaller cancerous lesions-many of which will be benign in biological behaviour-the need to design and evaluate strategies to inform and engage with the mainstream media and the public about cancer overdiagnosis risk is becoming more and more important.

Twitter Brooke Nickel @brooke_nickel

Contributors BN, RM, AB, JPB and KM conceived the study. BN, RM and KM were involved in designing the study and data analysis. BN drafted the manuscript. All authors contributed to the interpretation of the analysis, and critically revised and approved the manuscript.

Funding This project was supported by a National Health and Medical Research Council (NHMRC) Centre for Research Excellence Grant (1104136). KM is supported by an NHMRC Principal Research Fellowship (1121110).

Competing interests $\mathrm{RM}$ and $\mathrm{AB}$ are members of the Scientific Committee of Preventing Overdiagnosis international conferences. RM, $A B$ and $K M$ are lead investigators on Wiser Healthcare a research collaboration to reduce overdiagnosis and overtreatment.

Patient consent for publication Not required.

Ethics approval The study was approved by the University of Sydney Human Research Ethics Committee (2019/773).

Provenance and peer review Not commissioned; externally peer reviewed. Data availability statement № data are available.

Open access This is an open access article distributed in accordance with the Creative Commons Attribution Non Commercial (CC BY-NC 4.0) license, which permits others to distribute, remix, adapt, build upon this work non-commercially, and license their derivative works on different terms, provided the original work is properly cited, appropriate credit is given, any changes made indicated, and the use is non-commercial. See: http://creativecommons.org/licenses/by-nc/4.0/.

ORCID iD

Brooke Nickel http://orcid.org/0000-0002-8100-4278

\section{REFERENCES}

1 Welch HG, Black WC. Overdiagnosis in cancer. J Natl Cancer Inst 2010;102:605-13.

2 Glasziou PP, Jones MA, Pathirana T, et al. Estimating the magnitude of cancer overdiagnosis in Australia. Med J Aust 2020;2020.

3 Carter SM, Rogers W, Heath I, et al. The challenge of overdiagnosis begins with its definition. BMJ 2015;350:h869.

4 US Preventive Services Task Force, Grossman DC, Curry SJ, et al. Screening for prostate cancer: US preventive services Task force recommendation statement. JAMA 2018;319:1901-13.

5 Independent UK Panel on Breast Cancer Screening. The benefits and harms of breast cancer screening: an independent review. Lancet 2012;380:1778-86.

6 Vaccarella S, Franceschi S, Bray F, et al. Worldwide Thyroid-Cancer epidemic? the increasing impact of overdiagnosis. $N$ Engl J Med 2016;375:614-7.

7 Haugen BR, Alexander EK, Bible KC, et al. 2015 American thyroid association management guidelines for adult patients with thyroid nodules and differentiated thyroid cancer: the American thyroid association guidelines Task force on thyroid nodules and differentiated thyroid cancer. Thyroid 2016;26:1-133. 
8 Francis A, Fallowfield L, Rea D. The loris trial: addressing overtreatment of ductal carcinoma in situ. Clin Oncol 2015;27:6-8.

9 Elshof LE, Tryfonidis K, Slaets L, et al. Feasibility of a prospective, randomised, open-label, international multicentre, phase III, non-inferiority trial to assess the safety of active surveillance for low risk ductal carcinoma in situ - The LORD study. Eur $J$ Cancer 2015:51:1497-510.

10 Hwang ES, Hyslop T, Lynch T, et al. The comet (comparison of operative versus monitoring and endocrine therapy) trial: a phase III randomised controlled clinical trial for low-risk ductal carcinoma in situ (DCIS). BMJ Open 2019;9:e026797.

11 Fagerlin A, Zikmund-Fisher BJ, Ubel PA. Cure me even if it kills me: preferences for invasive cancer treatment. Med Decis Making 2005;25:614-9.

12 Nickel B, Brito JP, Barratt A, et al. Clinicians' views on management and terminology for papillary thyroid microcarcinoma: a qualitative study. Thyroid 2017;27:661-71.

13 Nickel B, Barratt A, McGeechan K, et al. Effect of a change in papillary thyroid cancer terminology on anxiety levels and treatment preferences: a randomized crossover trial. JAMA Otolaryngol Head Neck Surg 2018;144:867.

14 Nickel B, Barratt A, Hersch J, et al. How different terminology for ductal carcinoma in situ (DCIS) impacts women's concern and management preferences: a qualitative study. Breast 2015;24:673-9.

15 McCaffery K, Nickel B, Moynihan R, et al. How different terminology for ductal carcinoma in situ impacts women's concern and treatment preferences: a randomised comparison within a national community survey. BMJ Open 2015;5:e008094

16 Nickel B, Brito JP, Moynihan R, et al. Patients' experiences of diagnosis and management of papillary thyroid microcarcinoma: a qualitative study. BMC Cancer 2018;18:242.

17 Nickel B, Moynihan R, Barratt A, et al. Renaming low risk conditions labelled as cancer. BMJ 2018;362:k3322.

18 Goldacre B. Preventing bad reporting on health research. BMJ 2014;349:g7465

19 Moynihan R, Bero L, Ross-Degnan D, et al. Coverage by the news media of the benefits and risks of medications. $N$ Engl J Med 2000;342:1645-50.

20 Chapman S, McLeod K, Wakefield M, et al. Impact of news of celebrity illness on breast cancer screening: Kylie Minogue's breast cancer diagnosis. Med J Aust 2005;183:247-50.

21 Troiano G, Nante N, Cozzolino M. The Angelina Jolie effect - impact on breast and ovarian cancer prevention a systematic review of effects after the public announcement in may 2013. Health Educ J 2017;76:707-15

22 Weber RP. Basic content analysis. 2nd edn. Thousand Oaks, California: Sage, 1990
23 Kolata G. 'Cancer' or 'Weird Cells': Which Sounds Deadlier? The New York Times 2011;2011.

24 Kolata G. It's Not Cancer: Doctors Reclassify a Thyroid Tumor. The New York Times 2016;2016.

25 Nickel B, Semsarian C, Moynihan R, et al. Public perceptions of changing the terminology for low-risk thyroid cancer: a qualitative focus group study. BMJ Open 2019;9:e025820.

26 Hersch J, Jansen J, Barratt A, et al. Women's views on overdiagnosis in breast cancer screening: a qualitative study. BMJ 2013;346:f158.

27 Waller J, Douglas E, Whitaker KL, et al. Women's responses to information about overdiagnosis in the UK breast cancer screening programme: a qualitative study. BMJ Open 2013;3. doi:10.1136/ bmjopen-2013-002703. [Epub ahead of print: 22 Apr 2013].

28 Rychetnik L, Doust J, Thomas R, et al. A Community Jury on PSA screening: what do well-informed men want the government to do about prostate cancer screening--a qualitative analysis. BMJ Open 2014;4:e004682.

29 Moynihan R, Nickel B, Hersch J, et al. Public opinions about overdiagnosis: a national community survey. PLoS One 2015;10:e0125165

30 Park SH, Lee B, Lee S, et al. A qualitative study of women's views on overdiagnosis and screening for thyroid cancer in Korea. BMC Cancer 2015;15:858

31 Lee S, Lee YY, Yoon HJ, et al. Responses to overdiagnosis in thyroid cancer screening among Korean women. Cancer Res Treat 2016;48:883-91.

32 Schwartz LM, Woloshin S, Fowler FJ, et al. Enthusiasm for cancer screening in the United States. JAMA 2004;291:71-8.

33 Waller J, Osborne K, Wardle J. Enthusiasm for cancer screening in Great Britain: a general population survey. Br J Cancer 2015;112:562-6.

34 McCaffery KJ, Jansen J, Scherer LD, et al. Walking the tightrope: communicating overdiagnosis in modern healthcare. BMJ 2016;352:i348.

35 Moynihan R, Nickel B, Hersch J, et al. What do you think overdiagnosis means? A qualitative analysis of responses from a national community survey of Australians. BMJ Open 2015;5:e007436.

36 Ghanouni A, Meisel SF, Renzi C, et al. Survey of public definitions of the term 'overdiagnosis' in the UK. BMJ Open 2016;6:e010723.

37 Buchbinder R. Self-management education en masse: effectiveness of the Back Pain: Don't Take It Lying Down mass media campaign. Med J Aust 2008;189:S29-32.

38 Buchbinder R, Gross DP, Werner EL, et al. Understanding the characteristics of effective mass media campaigns for back pain and methodological challenges in evaluating their effects. Spine 2008;33:74-80. 